\title{
CCL2 affects fat metabolism in liver regeneration by regulating ADRP expression'1)
}

\author{
XUEKUN XING, HUI WAN, LAN ZHAO* \\ College of Public Health, Guilin Medical University, Guilin Guangxi, 541199, PR China \\ *Department of Life Sciences and Technology, Xinxiang Medical University, Xinxiang, Henan 453003, PR China
}

Xing X., Wan H., Zhao L.

CCL2 affects fat metabolism in liver regeneration by regulating ADRP expression

Summary

This study aimed to elucidate the effect of chemokine (c-c motif) ligand 2 (CCL2) on fat metabolism in liver regeneration. CCL2 shRNA expression plasmids were constructed and transfected into rats using hydraulic transgenic technology. Transfection efficiency was measured using a fluorescence microscope. We also measured serum levels of alanine aminotransferase (ALT) and aspartate aminotransferase (AST) to test liver functioning. The weights of regenerative livers were recorded and the liver index was calculated. We used immunohistochemistry to determine the expression of PCNA, and used western blot to measure expression levels of adipose differentiation related protein (ADRP). After transfection of pGenesil-1.0-ccl2 into the liver, expression levels of green fluorescent protein were $35 \%$ at $6 \mathrm{~h}$, and the liver index as well as levels of ALT, AST, PCNA, and ADRP were all lower than those in the group that underwent partial hepatectomy. We conclude that CCL2 may affect fat metabolism in liver regeneration by inhibiting the expression of ADRP.

Keywords: CCL2, fat metabolism, ADRP, liver regeneration

The liver is the only major organ in the adult body that has the ability to regenerate after injury. After the loss or injury of liver tissue caused by surgery, infection, poisoning or trauma, the remaining liver tissue can be restored to its original size and function in rats (15). Liver regeneration is an extremely complicated process, involving many cells, many factors, and many signal pathways. In the process of liver regeneration, energy metabolism is essential. As an important component of the body, adipose tissue is the main site for energy storage and oxidation, and it also has important significance for cell recognition and information transmission (10). Liver regeneration is often accompanied by fat accumulation (6-9).

$\mathrm{C}-\mathrm{C}$ chemokine ligand 2 (CCL2) was the first chemokine discovered by Valente in 1988 (23). CCL2, also named monocyte $(\mathrm{Mn})$ chemoattractant protein-1 (MCP-1), is secreted by injured Kupffer cells, stellate cells, hepatocytes due to massive accumulation of $\mathrm{Mn}$; it plays important roles in inflammatory responses,

1) This project was supported by research grants from Science and Technology Base and Talent Special Project of Guangxi Province (no. 2020AC20037), the cultivation plan for young backbone teachers in colleges and universities of Henan Province in 2019, and the project to improve the basic scientific research ability of young and middle-aged teachers in colleges and universities of Guangxi (no. 2020KY12008). angiogenesis, injury repair, and tumorigenesis $(11,18)$. CCL 2 has also been found to play important roles in the occurrence and development of many liver diseases, including hepatitis $(3,19)$, liver fibrosis (1) and liver cancer (13); nevertheless, its role in liver regeneration is not clear.

In the present study we constructed an interference plasmid of CCL2 and transferred it into a partial hepatectomy rat liver model using hydraulic transgenic technology, so as to preliminarily study the role of this protein in liver regeneration and to begin to clarify the mechanism of liver regeneration.

\section{Material and methods}

Experimental animals. Sprague Dawley (SD) rats, 200 $\pm 20 \mathrm{~g}$, male, 40 days, were raised at a constant temperature $\left(21-22^{\circ} \mathrm{C}\right)$ in an animal house. The rats were fed and watered ad libitum during the experiment. This study was conducted in accordance with the international guidelines for animal studies and obtained the approval of from the ethics committee of Xinxiang Medical University.

Construction of a CCL2 shRNA expression plasmid. Two single-stranded oligonucleotides were designed and synthesized from the cDNA sequence of CCL2 in GenBank (sequence number nm 031530.1). We used BamH I and Hind III to create the expression vector pGenesil-1.0 
plasmid (AXYBIO, China). After annealing, two singlestranded oligonucleotides were connected to pgenesil-1.0 for $18 \mathrm{~h}$, and then JM109 competent cells were transformed. Using double enzyme digestion identification and sequencing, the positive clone was named pGenesil-1.0-ccl2. The ShRNA fragment sequence was as follows:

ccl2 Sense:

5'-GATCCCAAAGAAGCTGTAGTATTTTTCAAGACGAAATACTACAGCTTCTTTGTTTTTTA-3'

ccl2 Anti-sense:

5'-AGCTTAAAAAACAAAGAAGCTGTAGTATTTCGTCTTGAAAAATACTACAGCTTCTTTGG-3'

Establishment of the partial hepatectomy model in rats. After the rats were anesthetized with pentobarbital sodium ( $40 \mathrm{mg} / \mathrm{kg}$ ), the hair on the abdomen and chest was removed. The rats were sterilized with ethanol and fixed on the operating table in the supine position. The skin was cut along the midline from $3 \mathrm{~cm}$ below the sternoxiphoid process to expose the abdominal cavity. The left lobe and middle lobe of liver (accounting for about $70 \%$ of total liver mass) was extruded. After ligation of the liver leaf root with silk thread, we excised the liver leaf, sutured the wound, and applied tetracycline powder to prevent infection.

Transfection efficiency observation. After partial hepatectomy in rats, pGenesil-1.0-ccl2 plasmid was transferred using the tail vein hydraulic transgenic method. At $6 \mathrm{~h}$ after partial hepatectomy, the rats were sacrificed using cervical dislocation. The right lobe of the liver was removed for frozen section, and the expression of green fluorescent protein was measured under fluorescence microscopy.

Liver function test. At $144 \mathrm{~h}$ after partial hepatectomy, 5 rats in each of the p pGenesil-1.0-ccl2 group and partial hepatectomy group were anesthetized using a pentobarbital sodium intraperitoneal injection, fixed in supine position, the abdominal cavity was opened, and $1 \mathrm{~mL}$ blood was collected from the inferior vena cava. The blood was collected at room temperature for $30 \mathrm{~min}$, centrifuged at $4000 \mathrm{r} / \mathrm{min}$ for $5 \mathrm{~min}$, and $300 \mu \mathrm{l}$ serum was collected. The content of alanine aminotransferase (ALT) and aspartate aminotransferase (AST) in the serum was measured using an automatic biochemical analyzer (Hitachi, Japan).

Liver index calculation. The weights of the rats and those of the regenerated livers were weighed at 48, 96, 144, 192,240 and $288 \mathrm{~h}$ after partial hepatectomy. The liver index was calculated according to the weight of the regenerated liver/body weight $\times 100 \%$.

Proliferating cell nuclear antigen (PCNA) positive cell rate test. After 48 hours of partial liver resection and recovery, the liver tissues were prepared into paraffin sections, dewaxed to water, treated with $3 \% \mathrm{H}_{2} \mathrm{O}_{2}$ at room temperature for $15 \mathrm{~min}$, modified with microwave antigen in citric acid buffer for $3 \mathrm{~min}$, sealed with $10 \%$ serum at $37^{\circ} \mathrm{C}$ for $30 \mathrm{~min}$, and then the liquid was aspirated. PCNA (Sigma, American, 1 : 100) was added and incubated overnight in a refrigerator at $4^{\circ} \mathrm{C}$. Secondary antibody (Sigma, American) was incubated at $37^{\circ} \mathrm{C}$ for $20 \mathrm{~min}$. SABC was incubated at $37^{\circ} \mathrm{C}$ for $20 \mathrm{~min}, \mathrm{DAB}-\mathrm{H}_{2} \mathrm{O}_{2}$ was developed, and neutral gum was used as a sealant. Ten fields were randomly selected and counted under microscopy, and the PCNA-positive cell rate was calculated according as PCNA- positive cell numbers in the field/total cell number in the cross section $\times 100 \%$.

The expression of fat-related proteins. After partial liver resection and recovery for 48, 96, 144, 192, 240 and $288 \mathrm{~h}$, the regenerated liver homogenate was centrifuged and collected for supernatant at $4^{\circ} \mathrm{C}, \mathrm{SDS}-\mathrm{PAGE}$ was used to separate the same amount of protein. The proteins were then transferred to the PVDF membrane. 5\% skim milk powder sealant was sealed for 1 hour, adipogenic differentiation-related protein (ADRP) (Abcam, England) was added, overnight at $4^{\circ} \mathrm{C}$, and $\beta$-actin was the internal reference protein. Horseradish peroxidase-labeled secondary antibodies (Abcam, England) were added and combined at room temperature for $1 \mathrm{~h}$. Beyo ECL Plus (Beyotime, China) chemiluminescence kit was used to develop bands.

Statistical analysis. SPSS 13.0 statistical software was used to conduct t-tests on the data of the experimental and control groups.

\section{Results and discussion}

Fat is one of the major energy sources in mammals. It plays important roles in normal cell growth and metabolism. Fatty acids can be broken down into carbon dioxide and water in the body, after which substantial amounts of energy are released in the form of ATP to be used by organisms. Fat accumulation occurs in liver tissue during liver regeneration $(6,17)$. In recent years, studies have found that lowering the accumulation of fat in liver regeneration through drug interventions or genetic changes can inhibit liver regeneration (20, 21, 24). However, the relationship between fat accumulation and liver regeneration, as well as the related signaling pathways, is unclear.

Adipogenic differentiation related protein (ADRP) is also known as perilipin-2 (PLIN2). It is a lipid droplet surface protein with a relative molecular weight of $48 \mathrm{kD}$, found in primate fat cells. ADRP is a surface protein of lipid droplets. It is widely expressed in almost all mammalian cultured cells, expressed in adipose tissue, liver, muscle, breast, pancreas, and small intestinal mucosa. ADRP is a major intracellular lipid droplet protein in the liver (16), and is expressed in both normal hepatocytes and astrocytes (22).

The content of ADRP positively correlated with the content of lipid in hepatocytes. PLIN2 knockout mice were resistant to obesity induced by a high-fat diet, inhibiting the formation of inflammatory lesions and steatosis in the white adipose tissue of the liver, and reducing energy intake (14). PLIN2 knockout also down-regulated the expression of genes related to adipogenesis and triglyceride synthesis, and inhibited alcohol-induced liver steatosis in mice (4). For these reasons, ADRP is considered a marker of liver lipid accumulation.

Kohjima et al. performed partial hepatectomy on ADRP knockout mice and found that the content of triglycerides in the liver decreased, cell cycle slowed down, beta-oxidation and fatty acids in the cytoplasm 
decreased, and liver regeneration slowed down. They also found reduced accumulation of liver fat and decreased cell proliferation in CCL4-induced ADRP knockout mice (12). They concluded that the accumulation and utilization of fat in the liver is beneficial to liver regeneration caused by partial hepatectomy and liver injury, and ADRP plays an important role in this process.

Clement et al. found that CCL2 can directly act on liver parenchymal cells and cause liver parenchymal cells to express phosphoenolpyruvate carboxykinase, promoting fatty acid esterification, and reducing the secretion of fat, resulting in cell fat accumulation (5). Ambade et al. showed that CCL2 caused the increase of ADRP in liver cells (2).

In this study, to investigate the role of CCL2 and ADRP in fat metabolism during liver regeneration, we constructed a plasmid pGenesil-1.0-ccl2. After partial hepatectomy in rats, the pGenesil-1.0-ccl2 plasmid was transferred using the tail vein hydraulic transgenic method. The expression of green fluorescent protein at $6 \mathrm{~h}$ after partial hepatectomy reached $35 \%$ (Fig. 1). It showed that CCL2 shRNA was highly expressed in the liver.

Venous blood was taken from the rats $144 \mathrm{~h}$ after partial hepatectomy to measure liver functioning. ALT and AST levels in the pGenesil-1.0-ccl2 group were not significantly different from those in the partial hepatectomy group (Tab. 1). After partial hepatectomy, the liver indexes of rats treated with the pGenesil-1.0ccl2 plasmid at 48, 96, 144, 192, 240 and $288 \mathrm{~h}$ were lower than those of the control group only undergoing partial hepatectomy, with a significant difference at $144 \mathrm{~h}$ (Fig. 2). The immunohistochemical results of

Tab. 1. Comparison of liver function

\begin{tabular}{|l|c|c|}
\hline \multicolumn{1}{|c|}{ Group } & ALT (U/L) & AST (U/L) \\
\hline PH & $83.42 \pm 5.13$ & $112.53 \pm 7.42$ \\
pGenesil-1.0-ccl2 & $76.92 \pm 8.46$ & $109.68 \pm 9.38$ \\
\hline
\end{tabular}

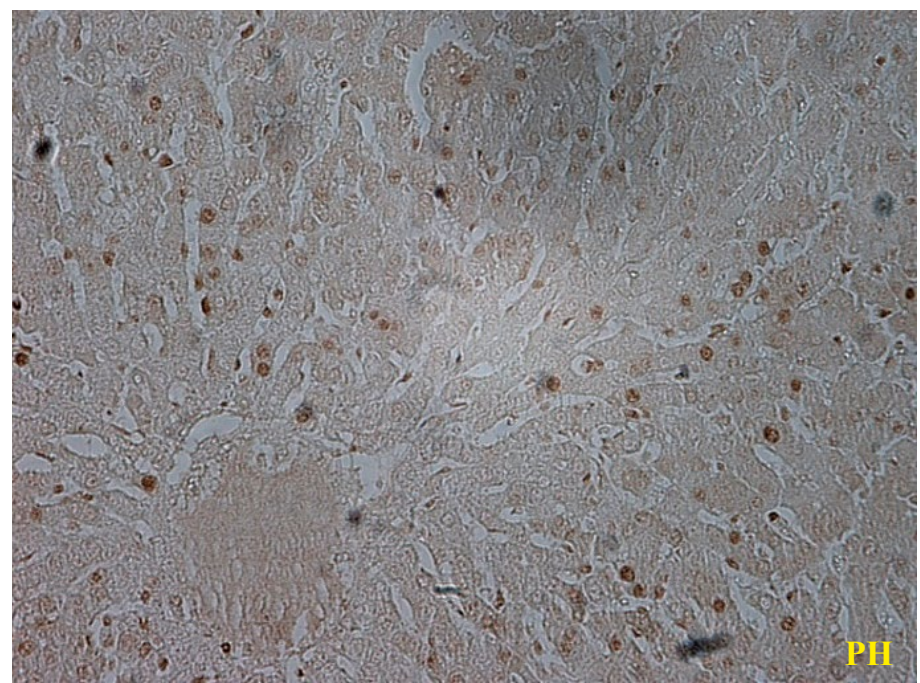

$48 \mathrm{~h}$ after partial hepatectomy showed that the PCNA positive cell rate was $14 \%$ in the partial hepatectomy group and $8 \%$ in the pGenesil-1.0-ccl2 group, slightly lower than that of the control group (Fig. 3). These experiments showed that decreased CCL 2 expression did not cause liver damage, but affected the rate of liver regeneration.

Western blotting results showed that, 48, 96, 144, 192, 240 and $288 \mathrm{~h}$ after partial hepatectomy, the

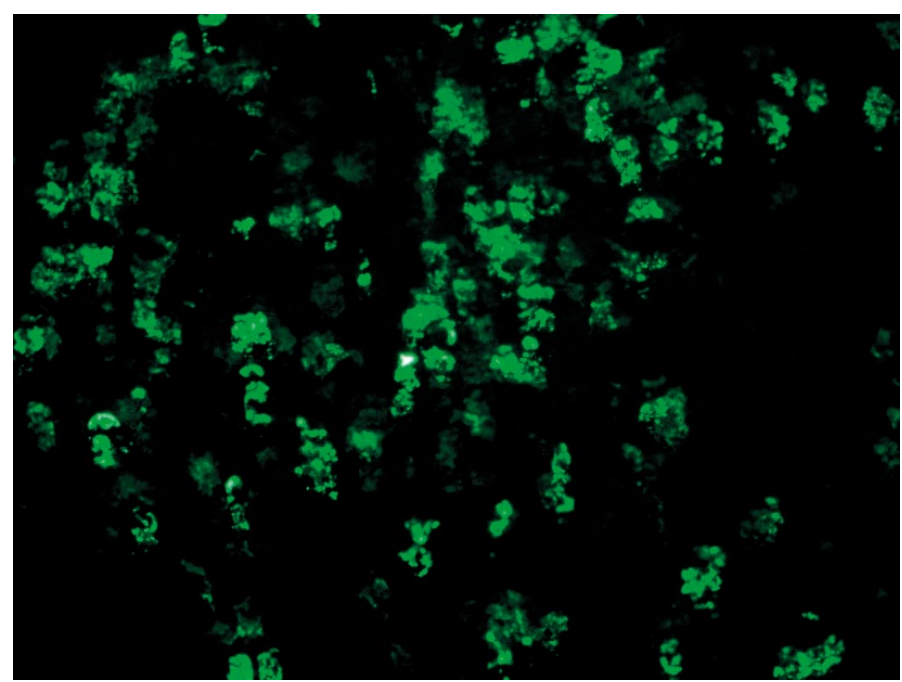

Fig. 1. Expression of pGenesil-1.0-ccl2 plasmid

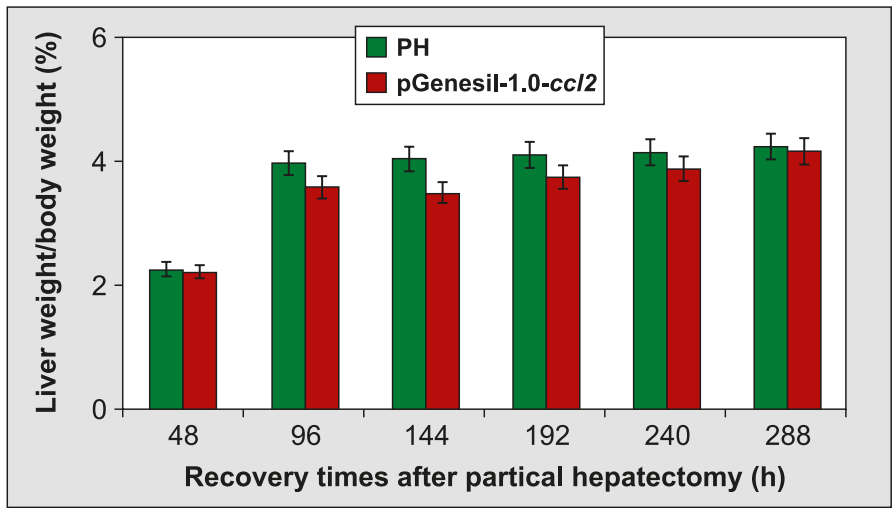

Fig. 2. Effect of CCL2 on liver index in rats

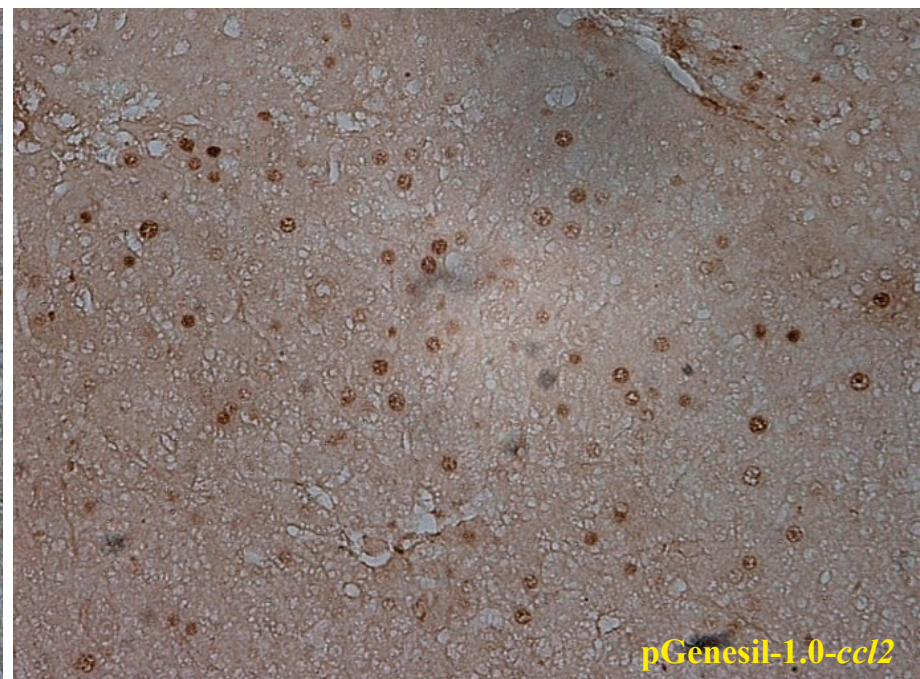

Fig. 3. Immunohistochemical results of PCNA 


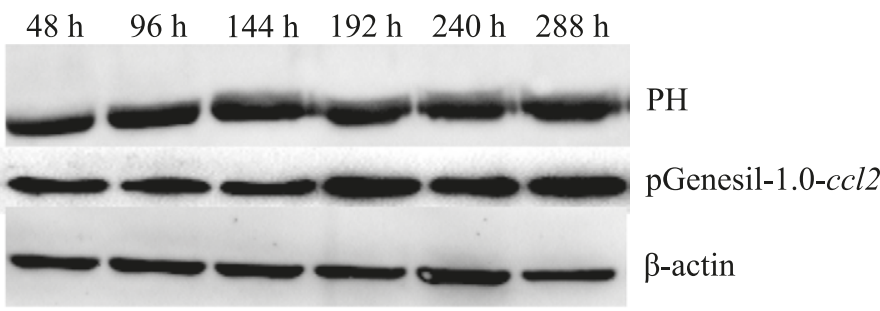

Fig. 4. Expression changes of ADRP were detected by western blotting

amounts of ADRP in the pGenesil-1.0-ccl2 group was lower than that of the group with partial hepatectomy only (Fig. 4). It indicated that CCL2 interference vector caused decreased ADRP expression, consistent with previous research results.

In conclusion, CCL 2 is a liver regeneration related protein that regulates the formation of fat and promotes liver regeneration by regulating the expression of its downstream protein ADRP. Nevertheless, the specific role of fat droplets in liver regeneration and the related molecular mechanisms need to be further studied.

\section{References}

1. Affo S., Sancho-Bru P.: CCL2: a link between hepatic inflammation, fibrosis and angiogenesis? Gut 2014, 63, 1834-1835.

2. Ambade A., Lowe P., Kodys K., Catalano D., Gyongyosi B., Cho Y., IrachetaVellve A., Adejumo A., Saha B., Calenda C., Mehta J., Lefebvre E., Vig P., Szabo G.: Pharmacological Inhibition of CCR2/5 Signaling Prevents and Reverses Alcohol-Induced Liver Damage, Steatosis, and Inflammation in Mice. Hepatology 2019, 69, 1105-1121.

3. Antonelli A., Ferri C., Fallahi P., Ferrari S. M., Frascerra S., Pampana A., Panicucci E., Carpi A., Nicolini A., Ferrannini E.: CXCL10 and CCL2 chemokine serum levels in patients with hepatitis $\mathrm{C}$ associated with autoimmune thyroiditis. J. Interferon. Cytokine. Res. 2009, 29, 345-351

4. Carr R. M., Peralta G., Yin X., Ahima R. S.: Absence of perilipin 2 prevents hepatic steatosis, glucose intolerance and ceramide accumulation in alcoholfed mice. PLoS. One 2014, 9, e97118.

5. Clement S., Juge-Aubry C., Sgroi A., Conzelmann S., Pazienza V., PittetCuenod B., Meier C. A., Negro F.: Monocyte chemoattractant protein-1 secreted by adipose tissue induces direct lipid accumulation in hepatocytes. Hepatology 2008, 48, 799-807.

6. Delahunty T. J., Rubinstein D.: Accumulation and release of triglycerides by rat liver following partial hepatectomy. J. Lipid. Res. 1970, 11, 536-543.

7. Girard A., Roheim P. S., Eder H. A.: Lipoprotein synthesis and fatty acid mobilization in rats after partial hepatectomy. Biochim. Biophys. Acta 1971, 248, 105-113.

8. Glende E. A., Jr., Morgan W. S.: Alteration in liver lipid and lipid fatty acid composition after partial hepatectomy in the rat. Exp. Mol. Pathol. 1968, 8, 190-200

9. Gove C. D., Hems D. A.: Fatty acid synthesis in the regenerating liver of the rat. Biochem. J. 1978, 170, 1-8.

10. Hemsworth J., Kumwenda C., Arimond M., Maleta K., Phuka J., Rehman A. M., Vosti S. A., Ashorn U., Filteau S., Dewey K. G., Ashorn P., Ferguson $E$. L.: Lipid-based nutrient supplements increase energy and macronutrient intakes from complementary food among malawian infants. J. Nutr. 2016, 146, 326-334.

11. Iwanaga N., Nakamura S., Oshima K., Kajihara T., Takazono T., Miyazaki T., Izumikawa K., Yanagihara K., Sugawara A., Sunazuka T., Omura S., Kohno S. Macrolides promote CCL2-mediated macrophage recruitment and clearance of nasopharyngeal pneumococcal colonization in mice. J. Infect. Dis. 2015, 212, 1150-1159.

12. Kohjima M., Tsai T. H., Tackett B. C., Thevananther S., Li L., Chang B. H., Chan L.: Delayed liver regeneration after partial hepatectomy in adipose differentiation related protein-null mice. J. Hepatol. 2013, 59, 1246-1254.

13. Li X., Yao W., Yuan Y., Chen P., Li B., Li J., Chu R., Song H., Xie D., Jiang X., Wang $H$.: Targeting of tumour-infiltrating macrophages via CCL2/CCR2 signalling as a therapeutic strategy against hepatocellular carcinoma. Gut 2017, $66,157-167$
14. McManaman J. L., Bales E. S., Orlicky D. J., Jackman M., MacLean P. S., Cain S., Crunk A. E., Mansur A., Graham C. E., Bowman T. A., Greenberg A. S.: Perilipin-2-null mice are protected against diet-induced obesity, adipose inflammation, and fatty liver disease. J. Lipid. Res. 2013, 54, 1346-1359.

15. Michalopoulos G. K.: Liver regeneration after partial hepatectomy: critical analysis of mechanistic dilemmas. Am. J. Pathol. 2010, 176, 2-13.

16. Motomura W., Inoue M., Ohtake T., Takahashi N., Nagamine M., Tanno S., Kohgo Y., Okumura T: Up-regulation of ADRP in fatty liver in human and liver steatosis in mice fed with high fat diet. Biochem. Biophys. Res. Commun. 2006, 340, 1111-1118.

17. Murray A. B., Strecker W., Silz S.: Ultrastructural changes in rat hepatocytes after partial hepatectomy, and comparison with biochemical results. J. Cell. Sci. 1981, 50, 433-448.

18. O'Connor T., Borsig L., Heikenwalder M.: CCL2-CCR2 signaling in disease pathogenesis. Endocr. Metab. Immune. Disord. Drug. Targets. 2015, 15, $105-118$

19. Sarma N. J., Tiriveedhi V., Crippin J. S., Chapman W. C., Mohanakumar T.: Hepatitis C virus-induced changes in microRNA 107 (miRNA-107) and miRNA-449a modulate CCL2 by targeting the interleukin-6 receptor complex in hepatitis. J. Virol. 2014, 88, 3733-3743.

20. Shteyer E., Liao Y., Muglia L. J., Hruz P. W., Rudnick D. A.: Disruption of hepatic adipogenesis is associated with impaired liver regeneration in mice. Hepatology 2004, 40, 1322-1332.

21. Srinivasan S. R., Chow C. K., Glauert H. P.: Effect of the peroxisome proliferator ciprofibrate on hepatic DNA synthesis and hepatic composition following partial hepatectomy in rats. Toxicology 1990, 62, 321-332.

22. Straub B. K., Stoeffel P., Heid H., Zimbelmann R., Schirmacher P.: Differential pattern of lipid droplet-associated proteins and de novo perilipin expression in hepatocyte steatogenesis. Hepatology 2008, 47, 1936-1946.

23. Valente A. J., Graves D. T., Vialle-Valentin C. E., Delgado R., Schwartz C. J.: Purification of a monocyte chemotactic factor secreted by nonhuman primate vascular cells in culture. Biochemistry 1988, 27, 4162-4168.

24. Walldorf J., Hillebrand C., Aurich H., Stock P., Hempel M., Ebensing S., Fleig W. E., Seufferlein T., Dollinger M. M., Christ B.: Propranolol impairs liver regeneration after partial hepatectomy in $\mathrm{C} 57 \mathrm{Bl} / 6$-mice by transient attenuation of hepatic lipid accumulation and increased apoptosis. Scand. J. Gastroenterol. 2010, 45, 468-476.

Corresponding author: Xing Xue-Kun, PhD, No. 1 Zhiyuan Road, Lingui District, Guilin City, Guangxi, 541199, China; e-mail: biyingxiao@163.com 